\title{
Can Quercetin be an Option for Treatment of Spinal Cord Injury? An Experimental Study
}

\author{
Ozgur OCAL ${ }^{1}$, Alp Ozgun BORCEK², Ozge PASAOGLU ${ }^{3}$, Ayse Cakir GUNDOGDU ${ }^{4}$, Gulnur TAKE KAPLANOGLU4 \\ Mustafa Kemali BAYKANER ${ }^{2}$
}

\author{
${ }^{1}$ Ankara Yildirim Beyazit University, Yenimahalle Education and Research Hospital, Ankara, Turkey \\ ${ }^{2}$ Gazi University, Faculty of Medicine, Department of Neurosurgery, Ankara, Turkey \\ ${ }^{3}$ Gazi University, Faculty of Medicine, Department of Biochemistry, Ankara, Turkey \\ ${ }^{4}$ Gazi University, Faculty of Medicine, Department of Histology, Ankara, Turkey \\ Corresponding author: Ozgur OCAL ozkanocal@yahoo.com
}

\section{ABSTRACT}

\begin{abstract}
AIM: To determine the neuroprotective functions of quercetin and compare them with methylprednisolone in an experimental spinal cord injury model in rats.

MATERIAL and METHODS: Thirty male, Wistar rats were assigned to five experimental groups: sham $(n=6)$, trauma $(n=6)$, methylprednisolone $(n=6)$, single dose quercetin $(n=6)$, and multiple doses of quercetin $(n=6)$. An aneurysm clip compression method was used to produce spinal cord injury at level T7-9 after performing a laminectomy. In the sham group, only a laminectomy was performed. Clip compression was performed to the spinal cord after laminectomy in the trauma group. For Group 3, a single dose of intraperitoneal (ip) methylprednisolone $(30 \mathrm{mg} / \mathrm{kg})$ was administered after laminectomy and trauma. A single dose of ip quercet in $(100 \mathrm{mg} / \mathrm{kg}$ ) was administered after laminectomy and trauma in Group 4. For Group 5, multiple doses of ip quercetin (100 mg/kg) were administered on the first, second, and third days after laminectomy and trauma. Spinal cord and serum samples were obtained to measure the levels of malondialdehyde (MDA), nitric oxide (NO), total antioxidant levels (TAL) at the $72^{\text {nd }}$ hour. Neurofunctional examinations of all the rats according to Drummond and Moore criteria and inclined-plane tests to evaluate functional healing were performed. All rats were sacrificed via intracardiac blood depletion after the procedure.
\end{abstract}

RESULTS: Quercetin and methylprednisolone both increased plasma and tissue levels of NO and MDA, and decreased TAL, with a statistically significant difference $(\mathrm{p}<0.05)$. NO and MDA levels in plasma and tissue were significantly higher in the trauma group (Group 2) when compared to the sham group (Group 1), and TAL levels were significantly lower $(p<0.05)$. There was a statistically significant increase in the treatment group's inclined-plane test $(p<0.05)$, while there was no difference in motor examination evaluations.

CONCLUSION: The results of this experimental study suggest that quercetin can be thought as an option of treatment in spinal cord injury.

KEYWORDS: Quercetin, Methylprednisolone, Spinal cord injury, Rats

\section{INTRODUCTION}

$\mathrm{T}$ The spinal cord is an important part of the central nervous system as a bridge binding cranial centers and peripheral nerves with each other and the cerebrum and cerebellum. Spinal cord injury (SCl) is a significant clinicopathological condition that can lead to permanent deficit in the cord's normal motor, sensory, and autonomic functions and decrease life quality. Unfortunately, there is no known effective treatment for $\mathrm{SCl}$ acquired after trauma. The pathophysiological mechanism of acute $\mathrm{SCl}$ can be
Ozgur OCAL

(1) : $0000-0002-8985-2626$

Alp Ozgun BORCEK (D) : 0000-0002-6222-382X

Ozge PASAOGLU (D) : 0000-0002-5221-9034
Ayse Cakir GUNDOGDU (D) : 0000-0002-2466-9717

Gulnur TAKE KAPLANOGLU (1) : 0000-0002-4321-2709 
distinguished as primary and secondary damage. Primary damage is the mechanical disruption of axons and neurons, which cannot be recovered after trauma. This is followed by secondary damage that begins within minutes after trauma and continues for a long time. Secondary damage includes a variety of physiopathologic processes comprising increasing levels of excitatory calcium and amino acids, free oxygen radicals and some inflammatory markers $(5,6,17)$. Many pharmacological drugs have been used to attenuate secondary damage in recent years. Only methylprednisolone has been found to be an effective agent with positive effects on SCI (8). Quercetin is a kind of flavonoid that has antioxidant, anti-inflammatory, vasodilatory, immunomodulatory, antihistaminic, antitumor, and antiviral effects $(2,3,11,13,14,15)$.

In the current study, the efficiency and antioxidant properties of quercetin and methylprednisolone were compared in an experimental $\mathrm{SCI}$ model in rats.

\section{- MATERIAL and METHODS}

This study was performed at the animal breeding and experimental research laboratory. Ethical approval was obtained from the Gazi University Local Ethics Committee for Animal Experiments (approval number: 66332047604.01.02, date: 24.10 .2014$)$. Thirty male, 4-5 month old Wistar rats, microsurgical tools, and a surgical microscope (Zeiss, Germany) were used in the study. The rats were assigned to five experimental groups: sham $(n=6)$, trauma $(n=6)$, methyl prednisolone $(n=6)$, single dose quercetin $(n=6)$, and multiple dose doses of quercetin $(n=6)$. An aneurysm clip compression method was used to produce spinal cord injuries at level T7-9 after performing a laminectomy. Spinal cord and serum samples were obtained to measure the levels of malondialdehyde (MDA), nitric oxide (NO), and total antioxidant levels (TAL) at the $72^{\text {nd }}$ hour after the interventions.

\section{Anesthesia and Surgery}

General anesthesia was ensured by an intramuscular injection of xylazine (5 mg/kg) (Rompun, Bayer, Istanbul, Turkey) and $50 \mathrm{mg} / \mathrm{kg}$ of ketamine hydrochloride (Ketalar, Pfizer, Istanbul, Turkey) twice before surgery, and before sacrifice. The doses of xylazine used did not have any myorelaxant effects so all of the rats breathed spontaneously. Therefore there was no need to intubate the rats nor to monitor blood oxygen concentrations. Rats were placed on fixing boards in a prone position after anesthesia. The thoracic area was shaved and povidone-iodine (Batticon solution; Adeka, Samsun, Turkey) was used for surface sterilization. Skin, subcutaneous and fascial tissues were passed via a $4 \mathrm{~cm}$ midline linear incision along the $\mathrm{T} 5$ to $\mathrm{L} 2$ spinal processes. After dissection of the paravertebral muscles, T7-T9 laminas were exposed. A T7, 8 , and 9 laminectomy was performed and the dura left intact. The dura and spinal cord were totally clipped for one minute via an aneurysm clip (Yasargil FE 721; Aesculap, Tuttlingen, Germany) with a closing pressure of $70 \mathrm{~g}$, as described by Rivlin and Tator, for groups 2, 3, 4, and 5. Paraplegia was observed in all rats where trauma was performed. The paravertebral muscles and the skin were primarily closed with
3/0 vicryl according to anatomic layers. In the sham group only laminectomy was performed (Group 1). Clip compression was performed to the spinal cord after laminectomy in the trauma group (Group 2). A single dose of intraperitoneal (ip) methylprednisolone $(30 \mathrm{mg} / \mathrm{kg})$ was administered 30 minutes after the laminectomy and trauma in Group 3. A single dose of ip quercetin $(10 \mathrm{mg} / \mathrm{kg}$ ) was administered 30 minutes after the laminectomy and trauma in Group 4. In Group 5, multiple doses of ip quercetin $(100 \mathrm{mg} / \mathrm{kg})$ were administered after the laminectomy and trauma on the first, second and third days. All the animals were kept in separate cages in a temperaturecontrolled room with appropriate food and water until the end of the study. At the end of the $72^{\text {nd }}$ hour, the rats were sacrificed via intracardiac blood depletion under general anesthesia. Plasma and spinal cord samples were obtained for histopathologic and biochemical examination.

\section{Clinical Motor Examination}

We periodically performed neurofunctional examinations of all the rats according to the Drummond and Moore criteria $(0=$ paraplegia, no motor functions of hindlimb; $1=$ minimal motor functions against gravity; 2=mild motor function of hindlimb, the force against gravity is good but cannot take its lag under its body; $3=$ motor function of hindlimb is good, can take its lag under its body, can jump but not totally normal; 4=normal motor function) and inclined-plane tests to evaluate functional healing. All the rats underwent clinical motor examination four times; before the surgical procedure and 24, 48, and 72 hours after the procedure. The inclined-plane test is a commonly used method for experimental, acute spinal cord injury models defined by Rivliv and Tator. The rats were placed on a smooth-surfaced plane placed parallel to the floor that could be inclined up to 60 degrees. The inclination of the plane was increased by ten degrees and the highest angle the animal could stand on for 5 seconds without falling was accepted as the inclined plane angle. The inclined-plane test was applied to all groups before surgery and 24,48 , and 72 hours after surgery.

\section{Biochemical Analysis}

The plasma levels of NO, which is a free radical produced from L-Arginine, was measured with a BioAssay Systems'

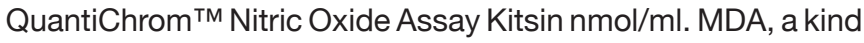
of indicator of lipid peroxidation, interacts with thiobarbituric acid. The level of plasma MDA was detected by measuring the intensity of the MDA and thiobarbituric acid mixture with a spectrophotometer at a wavelength of $532 \mathrm{~nm}$ in $\mathrm{nmol} / \mathrm{ml}$. The total antioxidant level (TAL) of plasma was measured via Rel Assay Diagnostics Kits with a spectrophotometer at a wavelength of $660 \mathrm{~nm}$.

\section{Histopathological Analysis}

The rats' skin stitches were removed and the incisions were reopened at the third day. After dissection of the paravertebral muscles, a tissue sample of spinal cord, approximately $2 \mathrm{~cm}$ around the trauma region, was obtained. All tissue samples were fixed in $10 \%$ formaldehyde solution for light microscopy examination. Following the fixation, the tissue samples in the tapes were washed under running water for 24 hours. To 
remove water from the tissue samples, they were exposed to increasing degrees of alcohol series. After applying xylol, the tissues were embedded in paraffin and 4-5 $\mu \mathrm{m}$ thick sections were obtained. All samples were stained with hematoxylin eosin (H\&E) and evaluated with a Leica Q Vin 3 program.

\section{Statistical Analysis}

All statistical analyses were performed with IBM SPSS (Version 20; SPSS Inc., Evanston, IL, USA). Descriptive statistics were used for the findings. The ANOVA test was used to evaluate the parametric data. According to post-hoc analysis results, Tukey HSD was used for homogenous variances and Tamhane's test was used for non-homogenous variances. The results are presented as mean \pm standard deviation, and $p<0.05$ was accepted as statistically significant.

\section{RESULTS}

\section{Biochemical Results}

The plasma and tissue levels of NO, MDA, and TAL for each group are shown in Table I. According to these results, the NO and MDA levels in plasma and tissue were significantly higher in the trauma group (Group 2) than in the sham group (Group
1) while the TAL levels were significantly lower $(p<0.05)$. There was a statistically significant decrease in plasma and tissue levels of NO and MDA, and a statistically significant increase in plasma and tissue levels of TAL in the treatment groups (Groups 3, 4, and 5) compared to the trauma group $(p<0.05)$. No significant difference was found between treatment groups ( $>0.05)$.

\section{Results of Inclined-Plane Test}

The analysis of the inclined-plane test is shown in Table II. The results were significantly lower in the trauma group compared to the sham group $(p<0.05)$. In the treatment groups there was a significant increase compared to the trauma group $(p<0.05)$. No significant difference was found between the treatment groups $(p>0.05)$.

\section{Histopathological Results}

According to the histopathologic evaluation, grey and white matter were normally observed in the sham group (Figure 1). In the trauma group, the tissue integrity was disrupted. There was massive inflammation in the area of the grey matter. Canalis centralis and ependymal cells were not seen (Figure 2). Common edema was observed in the myelinated nerve fibers in the white matter. In groups 3,4 , and 5 , there

Table I: The Plasma and Tissue Levels of NO, MDA, and TAL for Each Group

\begin{tabular}{|c|c|c|c|c|c|c|c|}
\hline & & $\begin{array}{l}\text { SERUM } \\
\text { NO }\end{array}$ & $\begin{array}{c}\text { TISSUE } \\
\text { NO }\end{array}$ & $\begin{array}{c}\text { SERUM } \\
\text { MDA }\end{array}$ & $\begin{array}{l}\text { TISSUE } \\
\text { MDA }\end{array}$ & $\begin{array}{l}\text { SERUM } \\
\text { TAL }\end{array}$ & $\begin{array}{c}\text { TISSUE } \\
\text { TAL }\end{array}$ \\
\hline \multirow{5}{*}{ Group 1 (Laminectomy) } & Mean & 93.82 & 133.17 & 23.60 & 18.77 & 1.34 & 11.47 \\
\hline & Median & 42.85 & 22.56 & 3.43 & 6.56 & 0.31 & 1.93 \\
\hline & Std. Deviation & 103.25 & 137.55 & 23.35 & 17.22 & 1.27 & 11.23 \\
\hline & Minimum & 38.80 & 96.30 & 18.50 & 11.67 & 1.00 & 9.44 \\
\hline & Maximum & 137.00 & 163.80 & 28.20 & 28.33 & 1.88 & 14.25 \\
\hline \multirow{5}{*}{$\begin{array}{l}\text { Group } 2 \\
\text { (Laminectomy+Clip) }\end{array}$} & Mean & 291.27 & 199.68 & 40.93 & 39.05 & 0.94 & 7.95 \\
\hline & Median & 101.80 & 61.57 & 6.38 & 13.62 & 0.22 & 1.43 \\
\hline & Std. Deviation & 323.25 & 193.15 & 40.48 & 35.74 & 0.91 & 7.55 \\
\hline & Minimum & 149.40 & 127.50 & 32.50 & 24.23 & 0.66 & 6.44 \\
\hline & Maximum & 416.80 & 285.00 & 50.52 & 58.05 & 1.24 & 10.01 \\
\hline \multirow{5}{*}{$\begin{array}{l}\text { Group } 3 \\
\text { (Laminectomy+Clip+Methylpre } \\
\text { dnisolone) }\end{array}$} & Mean & 178.88 & 145.12 & 31.50 & 26.01 & 1.45 & 11.87 \\
\hline & Median & 29.95 & 30.15 & 2.75 & 9.41 & 0.40 & 1.90 \\
\hline & Std. Deviation & 174.10 & 142.70 & 31.03 & 25.34 & 1.31 & 11.79 \\
\hline & Minimum & 143.30 & 98.50 & 28.24 & 13.52 & 1.06 & 9.44 \\
\hline & Maximum & 222.80 & 185.00 & 35.24 & 41.20 & 2.10 & 14.21 \\
\hline \multirow{5}{*}{$\begin{array}{l}\text { Group } 4 \\
\text { (Laminectomy+Clip+single } \\
\text { dose of Quercetin) }\end{array}$} & Mean & 124.73 & 162.04 & 32.17 & 20.91 & 1.68 & 12.32 \\
\hline & Median & 38.69 & 23.06 & 3.15 & 6.29 & 0.23 & 1.86 \\
\hline & Std. Deviation & 139.45 & 167.90 & 32.13 & 20.93 & 1.70 & 12.01 \\
\hline & Minimum & 61.40 & 125.50 & 28.05 & 13.52 & 1.40 & 9.98 \\
\hline & Maximum & 165.90 & 190.25 & 36.20 & 30.33 & 1.98 & 15.45 \\
\hline \multirow{5}{*}{$\begin{array}{l}\text { Group } 5 \\
\text { (Laminectomy+Clip+multiple } \\
\text { doses of Quercetin) }\end{array}$} & Mean & 168.25 & 135.22 & 32.61 & 23.39 & 1.41 & 11.19 \\
\hline & Median & 42.33 & 44.20 & 4.01 & 4.79 & 0.17 & 1.28 \\
\hline & Std. Deviation & 180.80 & 134.40 & 32.10 & 22.78 & 1.37 & 11.32 \\
\hline & Minimum & 98.10 & 82.50 & 28.00 & 18.20 & 1.25 & 9.40 \\
\hline & Maximum & 224.50 & 205.00 & 38.20 & 30.44 & 1.69 & 12.61 \\
\hline
\end{tabular}

NO: Nitric oxide, MDA: Maloxdialtehyde, TAL: Total antioxidant levels. 
Ocal O. et al: Quercetin in Spinal Cord Injury

Table II: The Analysis of the Inclined-Plane Test

\begin{tabular}{|c|c|c|c|c|c|}
\hline EXPERIMENT GROUP & & \multicolumn{4}{|c|}{ TIME** } \\
\hline \multirow{3}{*}{ Group 1 (Laminectomy) } & Mean & 60.00 & 60.00 & 60.00 & 60.00 \\
\hline & Std.Deviation & 0.00 & 0.00 & 0.00 & 0.00 \\
\hline & Minimum & 60.00 & 60.00 & 60.00 & 60.00 \\
\hline \multirow{4}{*}{$\begin{array}{l}\text { Group } 2 \\
\text { (Laminectomy+Clip) }\end{array}$} & Median & 60.00 & 30.00 & 40.00 & 60.00 \\
\hline & Std.deviation & 0.00 & 5.16 & 4.08 & 15.49 \\
\hline & Minimum & 60.00 & 30.00 & 30.00 & 30.00 \\
\hline & Maximum & 60.00 & 40.00 & 40.00 & 60.00 \\
\hline $\begin{array}{l}\text { Group } 3 \\
\text { (Laminectomy+Clip+ } \\
\text { Methylprednisolone) }\end{array}$ & Mean & 60.00 & 42.50 & 50.00 & 50.00 \\
\hline \multirow{5}{*}{$\begin{array}{l}\text { Group } 4 \\
\text { (Laminectomy+Clip+single dose } \\
\text { of Quercetin) }\end{array}$} & Mean & 60.00 & 45.00 & 45.83 & 46.67 \\
\hline & Median & 60.00 & 45.00 & 45.00 & 47.50 \\
\hline & Std.Deviation & 0.00 & 3.16 & 3.76 & 4.08 \\
\hline & Minimum & 60.00 & 40.00 & 40.00 & 40.00 \\
\hline & Maximum & 60.00 & 50.00 & 50.00 & 50.00 \\
\hline \multirow{5}{*}{$\begin{array}{l}\text { Group } 5 \\
\text { (Laminectomy+Clip+multiple } \\
\text { doses of Quercetin) }\end{array}$} & Mean & 60.00 & 42.50 & 43.33 & 44.17 \\
\hline & Median & 60.00 & 40.00 & 42.50 & 45.00 \\
\hline & Std.Deviation & 0.00 & 4.18 & 4.08 & 3.76 \\
\hline & Minimum & 60.00 & 40.00 & 40.00 & 40.00 \\
\hline & Maximum & 60.00 & 50.00 & 50.00 & 50.00 \\
\hline
\end{tabular}

*Kruskal-Wallis $\mathrm{H}$ test. ** Time after laminectomy.

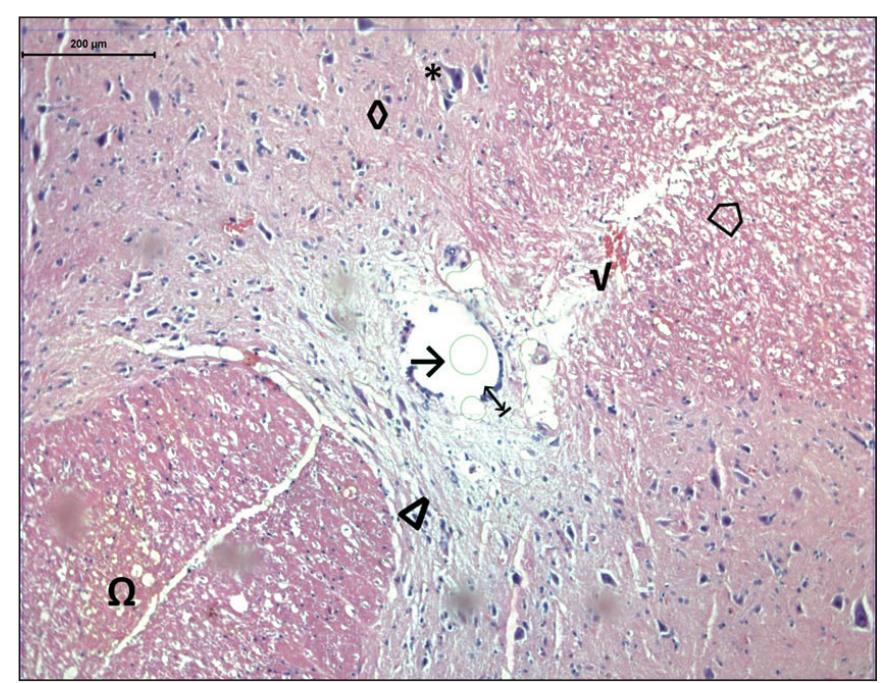

Figure 1: Group 1; white matter $(\triangle)$, gry matter $(\Delta)$, canalis centralis $(\rightarrow)$, ependimal cells $(\uparrow)$, multipolarmotorneurons $\left({ }^{*}\right)$, gliacells $(0)$, myelinated nerve fibers $(\Omega)$, blood vessels $(\sqrt{ })$ (Hematoxylin Eosin x100).

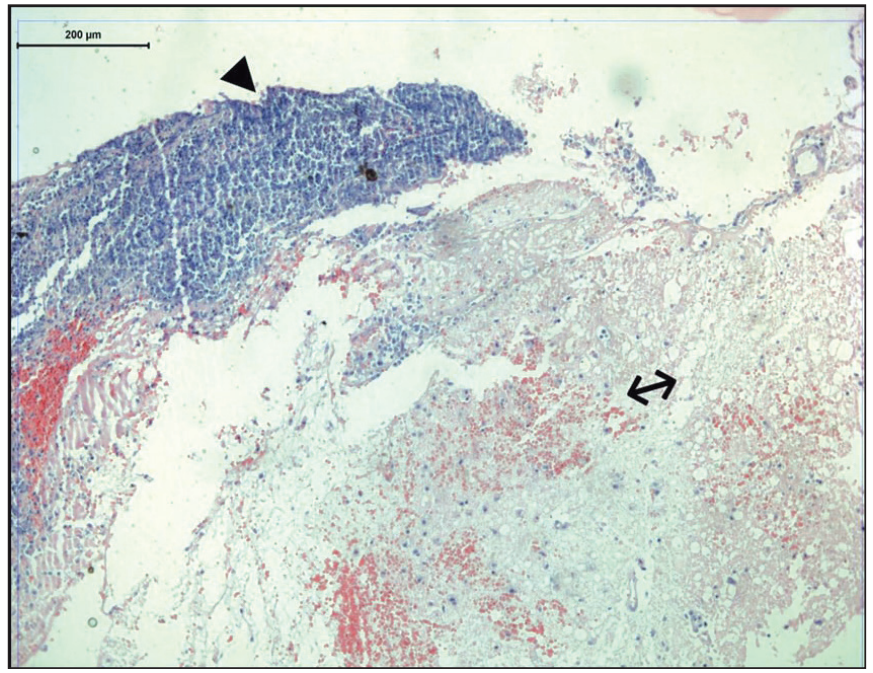

Figure 2: Group 2; massive inflammation $(\rightarrow$ ) and massive edema of myelinated nerve fibers $(\uparrow)$ (Hematoxylin Eosin x100). 


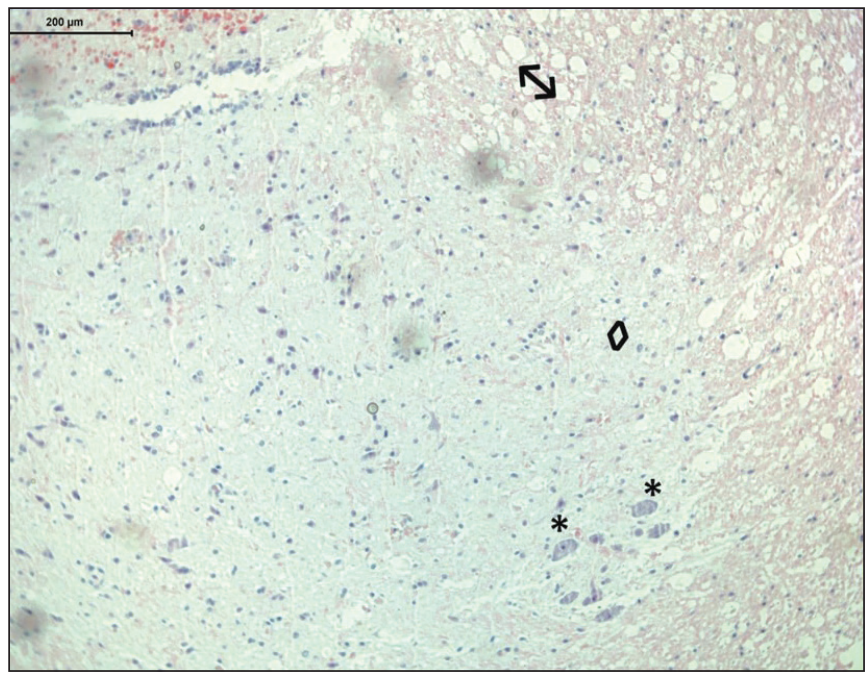

Figure 3: Group 3; multipolar motor neurons $\left({ }^{*}\right)$, glia cells $(\diamond)$ and massive edema of myelinated nerve fibers $(\uparrow)$ (Hematoxylin Eosin $\mathrm{x} 100)$.

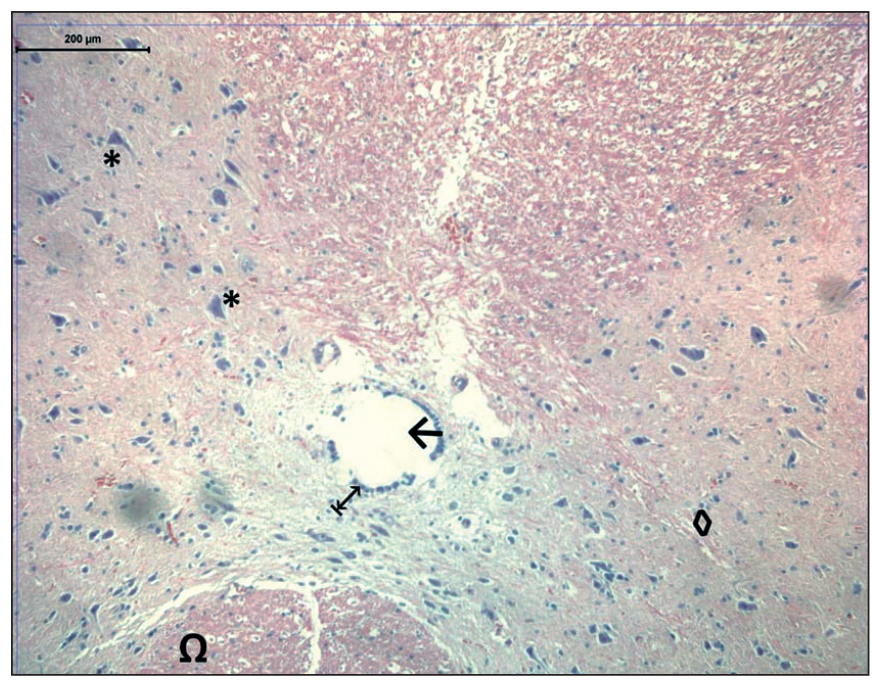

Figure 5: Group 5; multipolar motor neurons $\left(^{*}\right)$, glia cells $(0)$, myelinated nerve fibers $(\Omega)$, canalis centralis $(\rightarrow)$ and epandymal cells $(\uparrow)$ (Hematoxylin Eosin x100).

was no inflammation, but there was an increase in multipolar motor neurons compared to the trauma group, but nissl body accumulation had not reached normal (Figure 3-5). Glia cell distribution was normal. There was a decrease in edema of myelinated nerve fibers in Group 3 compared to the trauma group, and an increase compared to Group 4 and 5.

\section{Results of Clinical Motor Examination}

The clinical motor examination results are shown in Table III. There was a statistically significant decrease in the trauma group compared to the sham group $(p<0.05)$. The results of the treatment groups were not significantly different from the trauma group $(p>0.05)$.

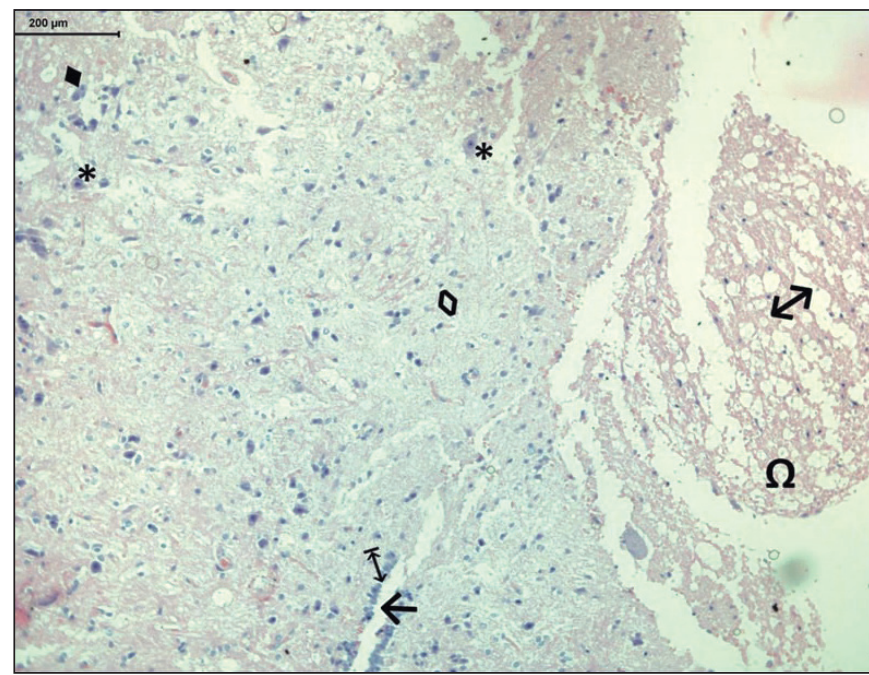

Figure 4: Group 4; multipolar motor neurons (*), periperically localized nissle bodies $(\diamond)$, glia cells $(\diamond)$, miyelinated nerve fibers $(\Omega)$, massive edema of myelinated nerve fibers $(\uparrow)$, canalis centralis $(\rightarrow)$ and epandymal cells $(\uparrow)$ (Hematoxylin Eosin x100).

\section{- DISCUSSION}

The current study demonstrated significant differences among groups in favor of methylprednisolone and quercetin regarding NO, MDA, and total antioxidant status (TAS) levels. Histopathological analyses were also in favor of the treatment groups. MP and quercetin both reduced posttraumatic spinal cord edema, neutrophil infiltration, and improved functional recovery. Despite observing significant healing in the treatment groups, the inclined-plane test results showed there was no difference in the results of clinical motor examination between trauma and treatment groups. Although it was a confusing result, we believe that during the inclined plane test, the rats used both upper and lower extremities while the clinical motor examination examines only the extremity that is evaluated. The success of rats on the inclined plane test could be due to the healthy upper extremities. In a previous study investigating the efficacy of quercetin in an experimental traumatic spinal cord injury model, Schültke et al. found that the longer treatment was more effective than the shorter treatment (15). In our study, the reason for not observing improvement of motor functions despite the histopathological and biochemical results were supporting the healing effect of treatment may be the short duration of the treatment.

Many pharmacological agents have been used to treat $\mathrm{SCl}$ in experimental models so far. Almost all of these agents targeted the secondary pathophysiological mechanism pathways, which include oxidative stress inflammatory processes, edema, ischemia, apoptosis, and tissue necrosis $(7,10,18)$. The oxidizing species and hydrolases occurring after trauma react with healthy tissue structures and increase the injured area $(9,12)$. An agent with antioxidant and anti-inflammatory effects might be a potentially effective therapeutic agent in the acute phase of SCl. 
Table III: The Clinical Motor Examination Results

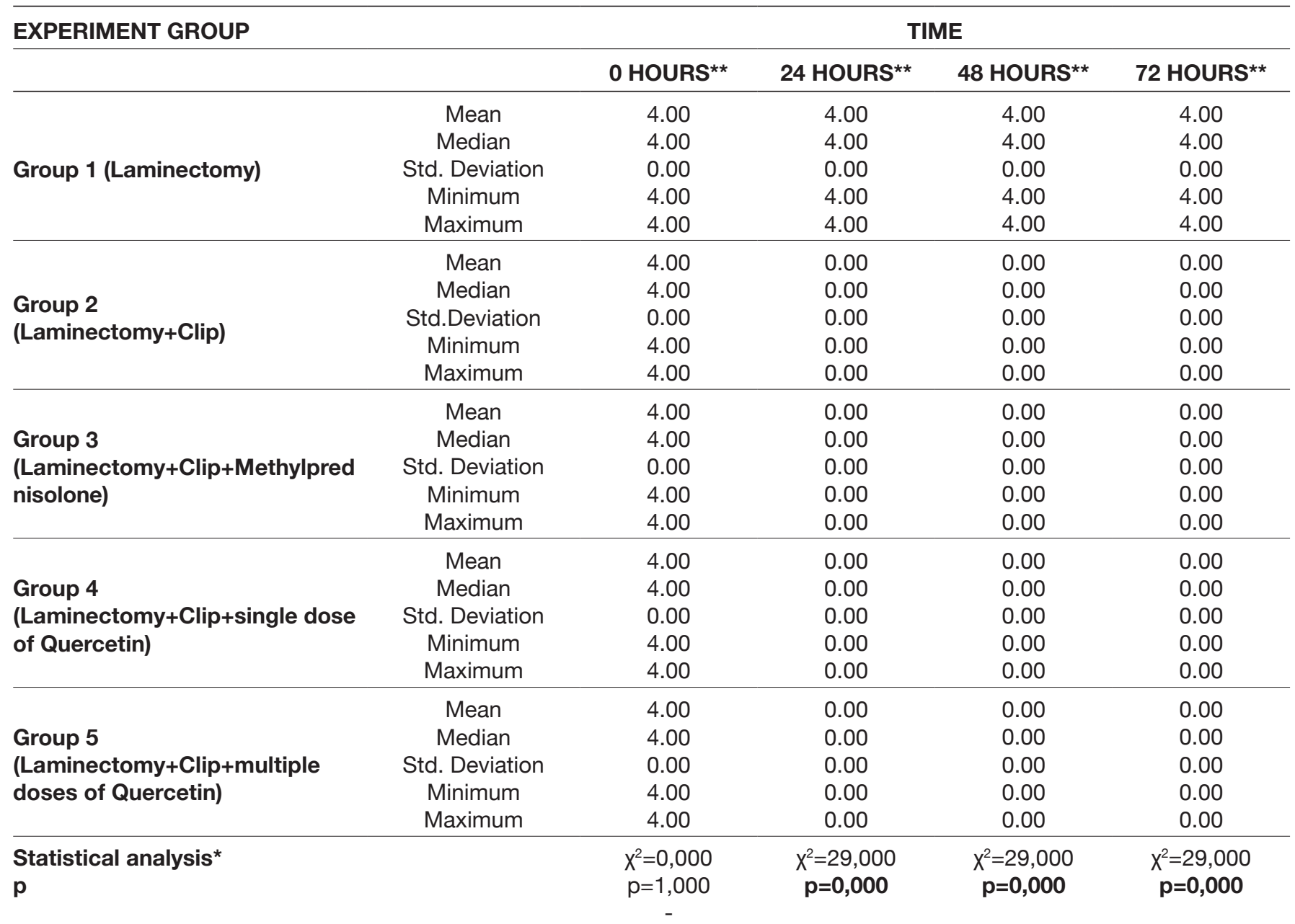

*Kruskal-Wallis $\mathrm{H}$ test, ** Time after laminectomy.

Methylprednisolone is the only agent that has been widely studied after SCls and neuroprotective effects have been shown. It reduces $\mathrm{SCl}$ by several mechanisms: inhibition of lipid peroxidation, providing protection from post-traumatic ischemia by regulating tissue blood supplementation; an aerobic energy mechanism, preventing accumulation of intracellular calcium; inhibition of vasoactive prostaglandin F2a; and thromboxane formation, reducing spinal neuronal excitability. The first large clinical study of methylprednisolone therapy for $\mathrm{SCl}$ was the National Acute Spinal Cord Injury Study (NASCIS) (1)

Quercetin is a well-defined flavonoid found in vegetables and fruits. It has antioxidant, anti-inflammatory, antiviral, anti-allergic, antithrombotic, atherosclerotic, and antitumor effects $(2,3,11,13,14,15)$. Previous studies have demonstrated that $\mathrm{SCl}$ results in increased activation of mitogen activated protein (MAP) kinases at the injury site of the spinal cord and quercetin normalizes the MAP kinase activation state (16). The mechanism of the neuroprotective effect of quercetin is not known, but quercetin possibly stabilizes lipid membranes and protects lipid peroxidation by scavenging free radicals and decreases leucocyte counts. Quercetin also inhibits oxidative enzymes, thus attenuating oxidative stress, which is a possible initial process of free radical-induced cellular damage $(14,15)$.

In this study, there was no additional healing in the multiple quercetin dose group compared to other treatment groups, according to biochemical, histopathological, and clinical criteria. In contrast, Schültke et al. found a correlation between treatment duration and recovery of motor function; a significant improvement in recovery of motor function was seen when the duration of quercetin administration was increased from 24 hours to 3 days (15).

Similar to the current study, Çiftçi et al. found that quercetin was as effective as methylprednisolone for biochemical and histopathological findings after a single dose administration. They demonstrated high tissue and serum TAS levels in a quercetin group compared to a control group (4).

\section{CONCLUSION}

This study suggests that quercetin is as effective as methylprednisolone for treatment of SCls in rats even with a 
single dose administration. In the first 72 hours, the treatment duration does not change the effectiveness of the drugs. Further studies with longer treatment durations are therefore needed.

\section{ACKNOWLEDGEMENTS}

We would like to thank Onur Akarca for her help in literature searching. We also affirm that everyone who contributed significantly to the work has listed.

\section{REFERENCES}

1. Bracken MB, Holford TR: Effecs of timing of methylprednisoloneornaloxone administration on recovery of segmental and long-tract neurological funtion in NASCIS 2. J Neurosurg 79(4):500-507,1993

2. Chattopadhyay $P$, Shukla G, Wahi AK: Ğrotective effect of L-arginine against necrosis and apoptosis induced by experimental ishcehimc and reperfusion in ratliver. Saudi $\mathrm{J}$ Gastroenterol 15:156-162, 2009

3. Çiftci O, Vardı N, Özdemir I: Effects of quercetin and chrys in on 2,3,7,8-tetrachlorodibenzo-p-dioxin induced hepatotoxicity in rats. Environ Toxicol 28:146-154, 2013

4. Çiftçi U, Delen E, Vural M, Uysal O, Coşan DT, Baydemir C, Doğaner F: Efficiacy of resveratrol and quercetin after experimental spinal cord injury. Ulus Travma Acil Cerrahi Derg 22(5):423-431, 2016

5. Faden Al, Simon RP: A potential role for excitotoxins in the pathophysiology of spinal cord injury. Ann Neurol 23(6):623626, 1988

6. Fehlings $\mathrm{MG}$, Tator $\mathrm{CH}$, Linden RD: The relation ships among the severity of spinal cord injury, motor and somato sensory evoked potentials and spinal cord blood flow. Electroencephalogr Clin Neurophysiol 74(4):241-259, 1989

7. Gerndt SJ, Rodriguez JL, Pawlik JW, Taheri PA, Wahl WL, Micheals AJ, et al: Consequencs of high-dose steroid therapy for acute spinal cord injury. J Trauma 42:279-284, 2001
8. Hugenholtz H, Cass DE, Dvorak MF, Fewer DH, Fox RJ, Izukawa DM, Lexhin J, Tuli S, Bharatwal N, Short C: High dose methylprednisolone for acute closed spinal cord injury: Only a treatment option. Can J Neurol Sci 29(3):227-235, 2002

9. Klebanoffsj: Oxygen metabolites from phagocytes. In: Galin JI, Snyderman R (eds). Inflammation: Basic Principles and Clinical Correlates. Philadelphia: Lippincott Williams\&Wilkins, 1999:721-768

10. Kopp MA, Liemscher T, Niedeggen A, Laufer S, Brommer $B$, Jungehulsing GJ, et al: Small-molecule-induced Rhoinhibition: NSAIDS after spinal cord injury. Cell Tissue Res 349:119-132, 2012

11. Moutsatsou P: The spectrum of phytoestrogens in nature: Our knowledge is expanding. Hormones (Athens) 6:173-193, 2007

12. Pincemail J, Deby C, Thirion A, De Btuyn-Dister M, Goutier $\mathrm{R}$ : Human myeloperoxidase activity is inhibited in vitro by quercetin. Comparison with three related compounds. Experientia 44:450-453, 1998

13. Rajevic N, Matkovic H, Gregorovic G, Kovacevic G, Knezovic L, Kalafatic M: Behavioral, morphological and histopathological effects of sublethaldoses of quercetin on the species Polycelicfelina (Dalyell). Folia Biol (Krakow) 28:146-154, 2013

14. Ross JA, Kasum CM: Dietary flavonoids: Bioavailability, metabolic effects, and safety. Annu Rev Nutr 22:19-34, 2002

15. Schültke E, Kamencic H, Skihar VM, Griebel R, Juurlink B: Quercetin in an animal model of spinal cord compression injury: Correlation of treatment duration with recovery of motor function. Spinal Cord 48:112-117, 2010

16. Selvakumar K, Bavithra S, Krishnamoorthy G, Venkataraman $\mathrm{P}$, Arunakaran J: Polychlorinatedbiphenyls-induced oxidative stres on rat hippocampus: A neuroprotective role of quercetin. Scientific World Journal 2012:980314, 2012

17. Tator $\mathrm{CH}$, Fehlings MG: Review of these condary injury theory of acute spinal cord trauma with emphasis on vascular mechanisms. J Neurosurg 75:15-26, 1991

18. Yin Y, Sun W, Li Z, Zhang B, Cui H, Deng L, et al: Effects of combining methylprednisolone with rolipram on functional recovery in adult rats following spinalc injury. Neurochem Int 62:903-912, 2013 